\title{
Antrials of Nutrition\& Metabolism
}

AgeingNutrition Group 62

Azpiroz, A. 72

Elmadfa, I. 1, 2, 38, 43, 47, 51, 54, 57, 72

Fabian, E. 57

Freisling, H. 43, 72

Fritz, K. 47

Genser, D. 29

Haber, P. 38

Hall, G. 25, 72

Hoffmann, A.T. 20

Jackson, S.H.D. 33

Kiely, M. 72

Koehler, J. 15

Kueck, M. 72

Kulnik, D. 51
Leonhaeuser, I.-U. 15

Lesser, S. 62

Matullat, I. 72

Meyer, A.L. 2

Mucci, E. 33

Norin, E. 12

Nutri-Senex Consortium 72

Pauly, L. 62

Stehle, P. 62

Sturtzel, B. 54

Topinková, E. 6

Volkert, D. 62

Wagner, K.-H. 38

Wendin, K. 25 